This item was submitted to Loughborough's Research Repository by the author.

Items in Figshare are protected by copyright, with all rights reserved, unless otherwise indicated.

\title{
Tributary connectivity, confluence aggradation and network biodiversity
}

PLEASE CITE THE PUBLISHED VERSION

http://dx.doi.org/10.1016/j.geomorph.2016.03.027

\section{PUBLISHER}

(c) Elsevier

VERSION

AM (Accepted Manuscript)

\section{PUBLISHER STATEMENT}

This work is made available according to the conditions of the Creative Commons Attribution-NonCommercialNoDerivatives 4.0 International (CC BY-NC-ND 4.0) licence. Full details of this licence are available at: https://creativecommons.org/licenses/by-nc-nd/4.0/

\section{LICENCE}

CC BY-NC-ND 4.0

\section{REPOSITORY RECORD}

Rice, Stephen. 2016. "Tributary Connectivity, Confluence Aggradation and Network Biodiversity". Loughborough University. https://hdl.handle.net/2134/20901. 
Tributary connectivity, confluence aggradation and network biodiversity

\author{
Stephen P Rice \\ Department of Geography, Loughborough University, Loughborough, LE11 3TU, UK \\ (s.rice@lboro.ac.uk)
}

Accepted GEOMORPHOLOGY March 2016

LUPIN repository version March 2016 


\section{ABSTRACT}

In fluvial networks, some confluences are associated with tributary-driven aggradation where coarse sediment is stored, downstream sediment connectivity is interrupted and substantial hydraulic and morphological heterogeneity is generated. To the extent that biological diversity is supported by physical diversity, it has been proposed that the distribution and frequency of tributary-driven aggradation is important for the magnitude and spatial structure of river biodiversity. Relevant ideas are formulated within the Link Discontinuity Concept and the Network Dynamics Hypothesis, but many of the issues raised by these conceptual models have not been systematically evaluated. This paper first tests an automated method for predicting the likelihood of tributary-driven aggradation in three large drainage networks in the Rocky Mountain foothills, Canada. The method correctly identified approximately $75 \%$ of significant tributary confluences and $97 \%$ of insignificant confluences. The method is then used to evaluate two hypotheses of the Network Dynamics Hypothesis: that linear-shaped basins are more likely to show a longitudinal, downstream decline in tributary-driven aggradation; and that larger and more compact basins contain more confluences with a high probability of impact. The use of a predictive model that included a measure of tributary basin sediment delivery, rather than symmetry ratio alone, mediated the outcomes somewhat, but as anticipated, the number of significant confluences increased with basin size and basin shape was a strong control of the number and distribution of significant confluences. Doubling basin area led to a 1.9-fold increase in the number of significant confluences and compact basins contained approximately twice as many significant confluences per unit channel length as linear basins. In compact basins, significant confluences were more widely distributed, whereas in linear basins they were concentrated in proximal reaches. Interesting outstanding issues include the possibility of using spatially-distributed sediment routing models to predict tributary-driven confluence aggradation and the need to gather ecological data sufficient to properly test for increases in local and network-scale biodiversity associated with significant confluences and their network-scale controls.

KEYWORDS: confluence, tributary, sedimentary link, Network Dynamics Hypothesis, river biodiversity 


\section{INTRODUCTION}

\subsection{Tributary-driven aggradation in river networks}

Confluences are nodal points of connectivity in the movement of water and sediment through a drainage network and the interaction of tributaries with their trunk streams is crucial for understanding sediment routing and maturation in river systems (Knighton, 1989; Benda and Dunne, 1997; Rice, 1998; Brierley and Fryirs, 1999; Mosley and Schumm, 2001; Fryirs et al., 2007; Fryirs, 2013). Some confluences, where tributaries supply particularly coarse and voluminous bed loads to their trunk stream, delineate "sedimentary links" that structure changes in slope, morphology and bed sediment character along individual drainage lines (Rice and Church, 1998; Rice, 1999). At these geomorphologically significant confluences, excess coarse sediment from active tributaries is stored in the mainstem channel (and associated tributary fans), forcing bed slope to steepen in order to maintain sediment dispersal downstream. Tributary-driven aggradation typically produces slope reductions and sediment fining upstream and slope steepening and sediment coarsening downstream (Miller, 1958; Church and Kellerhals, 1978; Rice and Church, 1998, 2001; Benda et al., 2004a; Harmer and Clifford, 2006; Hanks and Webb, 2006). These adjustments increase channel physical heterogeneity and, indeed, may be the primary driver of substrate, slope and morphological variability (Swanson and Meyer, 2014).

Augmentation of channel heterogeneity by tributary-driven aggradation has implications for river ecosystem functions and health because the additional habitat diversity may be an important support for biodiversity at local, reach and network scales (Benda, 2004b; Rice et al., 2006; Rice et al., 2008 for a review). Where aggradation is substantial, backwatering may produce upstream flow conditions characterised by lower velocities, deeper water and lower Froude numbers, contrasting with more energetic, higher Froude conditions on the steeper slope below the sediment supply point. In addition, excess sediment is available to build bedforms that add flow complexity and mesohabitats, and bed material sorting may generate diverse substrate characteristics (grain size, stability, microtopography, near-bed hydraulics) over short distances. This type of increased local heterogeneity at confluences has been associated with discontinuities in the longitudinal distribution and diversity of invertebrates (Rice et al., 2001; Knispel and Castella, 2003), periphyton and fish (Kiffney et 
al. 2006; Torgersen et al., 2008). In addition, the juxtaposition of contrasting physical conditions between the tributary, upstream and downstream links may offer unique opportunities for mobile taxa (Power and Dietrich, 2002), including for example, local (and therefore low-cost) access to contrasts in illumination, substrate stability, turbidity, predator avoidance and water temperature (Kupferberg, 1996; Scrivener et al., 1994; Fraser et al., 1995; Cairns et al., 2005; Katano et al., 2009; Taverny et al., 2012). There are other reasons why confluences are important for river biodiversity including: provision of nutrient or prey subsidies (Wipfli and Gregovitch, 2002; Fernandes et al., 2004; Wellard-Kelly, 2013); the presence of unique confluence-zone habitats (Nakamoto, 1994; Franks et al., 2002; Kreb and Budiono, 2005); the amplification of competition amongst species (Besemer et al., 2013); and bi-directional filtering that affects organism dispersal (e.g. Thornbrugh and Gido, 2010; Wilson and McTammany, 2014; Czeglédi et al., 2015). Confluences may therefore be biodiversity hotspots in river networks (Benda et al., 2004b), where added biological value partly reflects increased physical heterogeneity produced by tributary-forced aggradation.

However, it is clear that only some tributaries cause mainstem aggradation and measureable changes in geomorphology and ecology; many do not. Rice (1998) found that approximately $20 \%$ of tributaries along Pine and Sukunka Rivers in British Columbia, had an impact on mainstem grain size or slope. It is therefore unsurprising that some evaluations of tributary impacts on stream ecology are equivocal (e.g. Milesi and Melo, 2014; Clay et al, 2015). Ultimately, this reflects the complex nature of tributary-mainstem interactions and the lack of simple systematic relations between tributary properties and their impact (Rhoads, 1987; Wallis et al., 2008). In low order streams, bedrock controls on channel geometry, disruption of sediment connectivity by wood loading and direct coupling of the channel to hillslope sediment sources may mask tributary effects (Krumbein, 1942; Miller, 1958; Benda and Cundy 1990; Rice and Church, 1996; McEwen and Miller, 1998; Rengers and Wohl, 2007; Al Farraj and Harvey, 2010; Kuo and Brierley, 2014; Menting et al., 2015). In general, across all settings, tributary impacts on mainstem sediment storage may be transient (e.g. Kasai et al., 2005) and are contingent on local factors including degree of valley confinement, lithological variations, past depositional history and upstream sediment connectivity (Rice, 1998; Swanson and Meyer, 2014). For example, along the Sacramento River, California, basin physiography and anthropogenic interventions mean that upstream- 
downstream sediment connectivity is weak and tributaries devoid of sediment have no measurable impact on the mainstem (Singer, 2008).

\subsection{Controls of tributary-driven aggradation - which tributaries matter?}

If not all tributaries cause mainstem aggradation, but such aggradation is important, a key question is: What controls tributary-driven mainstem aggradation? Knighton (1980) argued that tributary sediment load and calibre were important determinants of step-changes in bed material grain size at confluences. Using field data from approximately 100 confluences in north-eastern British Columbia, Rice (1998) identified the product of tributary basin area and distal tributary slope $\left(\psi_{t}=A_{t} \cdot S_{t}\right)$ and the symmetry ratio $\left(A_{R}=A_{t} / A_{m}\right)$ as useful surrogate measures of tributary sediment delivery and relative bedload grain size, respectively (where $A_{t}$ is tributary basin area, $A_{m}$ is main stem basin area and $S_{t}$ is distal tributary slope). Logistic regression was used to establish an empirical relation for the probability of tributary impact on mainstem bed material size $P_{D}$ :

$$
\ln \left(\frac{P_{D}}{1-P_{D}}\right)=8.68+6.08 \log A_{R}+10.04 \log \varphi_{t}
$$

Benda et al. (2004a) investigated the properties of 168 tributary confluences that had been identified as geomorphologically significant in 14 separate studies from the western United States and Canada. They found that $A_{R}$ was a useful predictor of impact and defined logistic regression models for the probability of geomorphological impact $P_{G}$, for both humid and semi-arid environments, the former being:

$$
\ln \left(\frac{P_{G}}{1-P_{G}}\right)=3.79+1.96 \log A_{R}
$$

Both models [1] and [2] suggest that the probability of a tributary impact increases with $A_{R}$, but the data sets show that the bulk of significant confluences fall in the range $\left(0.01<A_{R}<\right.$ 0.1 ), such that very small tributaries, less than $1 / 100^{\text {th }}$ of the drainage area of the mainstem, and those approaching the same size as the mainstem are less frequently important.

Benda et al. (2004a) went on to consider the factors that affect the spatial distribution of relative tributary size in a drainage basin and therefore the spatial distribution of likely impacts across river networks, identifying three key factors. First, they argued that shape 
should be important, with heart-shaped or compact basin shapes more likely to experience tributary impacts in distal reaches than linear, rectangular shaped basins, because the former have a higher probability of hosting relatively large tributary basins along the entire length of the mainstem. Second, they argued that more densely dissected landscapes (therefore with a higher density of confluences) should have more frequent confluence effects. Third, they pointed out that structural constraints might complicate these general relations by affecting the spacing of tributaries and the angle at which confluent channels meet, with implications for the geomorphic impact (cf. Mosley, 1976; Benda and Cundy, 1990). The role of basin shape was illustrated using predictions of confluence impact based on equation [2], for two sub-catchments of the Siuslaw River, Oregon, and a systematic analysis revealed an anticipated increase in the spacing between significant confluences with distance downstream along the Siuslaw mainstem. Subsequently, Benda (2008) reflected on these analyses and extended them in several ways, identifying eight testable hypotheses pertaining to the impact of tributaries on mainstem geomorphology.

In addition to this empirical work, conceptual models of alluvial regime, for example Lane (1955), and theoretical investigations for both sand- and gravel-bed rivers (Ferguson and Hoey, 2008), suggest that mainstem responses to tributaries are governed by the ratios of tributary to mainstem discharge $\left(Q_{R}\right)$, bed load flux $\left(F_{R}\right)$ and bed load grain size $\left(D_{R}\right)$. In a numerical modelling experiment using a 1-D sediment routing model with a tributary input (TRIB), Ferguson et al. (2006) investigated the systematic variation of $Q_{R}, F_{R}$ and $D_{R}$ on mainstem geomorphology, measured as changes in channel slope and grain size. They found that patterns of bed gradation and grain-size change reflect the interplay between the sediment load that a tributary adds and the extra discharge available to transport it. Rice et al. (2006) used TRIB to explore the role of $Q_{R}, F_{R}$ and $D_{R}$ in generating physical heterogeneity around confluences, quantified as the amount of change in slope and grain size from upstream to downstream and within the upstream and downstream reaches. They found that the product $F_{R} \cdot D_{R}$ was the key determinant of such heterogeneity, while the momentum ratio $Q_{R}$ was less important (Rice et al., 2006). This result is consistent with field observations showing that tributaries which introduce large amounts of relatively coarse material are associated with mainstem storage, aggradation, upstream slope reduction and downstream slope increases (e.g. Rice and Church 1998, 2001; Swanston and Meyer 2014) 
and with the empirical relations for tributary impact produced by Rice (1998) and Benda et al. (2004a).

\subsection{Outstanding issues and aims}

Interesting questions about the controls of tributary-driven aggradation and its large-scale implications persist. This paper is concerned with two specific issues. First, is it possible to predict which confluences in a network are likely to exhibit tributary-driven aggradation? This is important because prediction would establish the likely location of geomorphologically significant storage nodes in a fluvial network and sites of enhanced physical heterogeneity and biodiversity. Various approaches to this problem could be taken, including the application of spatially distributed numerical models of sediment transfer processes (e.g. Gasparini, 1999; Sklar et al., 2006; Czuba and Foufoula-Georgiou, 2015) or the statistical interrogation of high-resolution or continuous, longitudinal data (Torgersen et al., 2008). Here, the approach adopted by Rice (1998) and Benda et al., (2004a) is pursued. An appropriate goal is to establish an automated method to predict likely confluence impact, based on extracting relevant predictive variables (e.g. $A_{R}, D_{R}, F_{R}$ ) from digital topographic data. Benda et al. (2004a) and Benda (2008) used such an approach to illustrate probable confluence impacts across the Siuslaw watershed, but the results were not systematically evaluated using field data. The first aim of this paper is therefore to:

1. evaluate whether an automated version of Rice's (1998) rule (equation 1) can correctly identify the confluences known to be geomorphologically significant along the mainstem of Sukunka River, British Columbia.

Because impacts on longitudinal grain size are driven by geomorphological adjustments to excess tributary sediment supply, $P_{D}$ values are regarded as probabilities of tributary-driven aggradation, even though equation 1 was formulated to detect changes in bed material grain size. Data from Sukunka River were used to define equation 1, so this aim amounts to an evaluation of how well an automated methodology can capture the key independent variables used by the model $\left(A_{R}, \psi_{t}\right)$. Also, it is not anticipated that the automated method can improve upon the performance of the manual method (Rice, 1998), rather it would make it possible to apply the method to a large number of confluences relatively quickly. 
The second issue considered here is how network size and shape affect the distribution and cumulative ecological benefit, in terms of additional physical heterogeneity, of tributarydriven aggradation. This is important because it might help to better understand differences in catchment-scale sediment routing and morphological diversity and (to the extent that physical heterogeneity underpins biodiversity) differences in sum, catchment-scale ecological value and resilience. Benda et al. (2004a, b) and Benda (2008) make an excellent case for such understanding, but empirical tests of their hypotheses have been limited. Following verification of aim 1, that an automated version of Rice's (1998) rule (equation 1) can correctly identify tributary-driven aggradation, that model will be applied across several additional drainage basins, to examine whether basin size and network shape (linear versus compact) affect the spatial distribution and cumulative magnitude of tributary derived heterogeneity. Specifically:

2. Do linear basins demonstrate the downstream decline in likelihood of tributary-driven aggradation proposed by Benda et al. (2004a)? Benda's hypothesis assumes that symmetry ratio (equation 2 ) is the only relevant control, but Rice's model also recognises the role of tributary sediment yield, as parameterised by $\psi_{t}$ (equation 1 ), and it is not clear what effect this will have on downstream patterns of tributary impact.

3. How does drainage network size and shape affect the frequency distribution of confluence impact probabilities and, in turn, the likely cumulative magnitude of confluence effects? Here, the expectation is that larger and more compact basins will contain more confluences with a high probability of an impact so that compact basins of a particular size have a greater overall confluence-related effect on heterogeneity.

\section{METHODS}

Aims 1 -3 were addressed using data for three river basins in north-eastern British Columbia, Canada: Sukunka, Pine and Murray Rivers (Figure 1). 


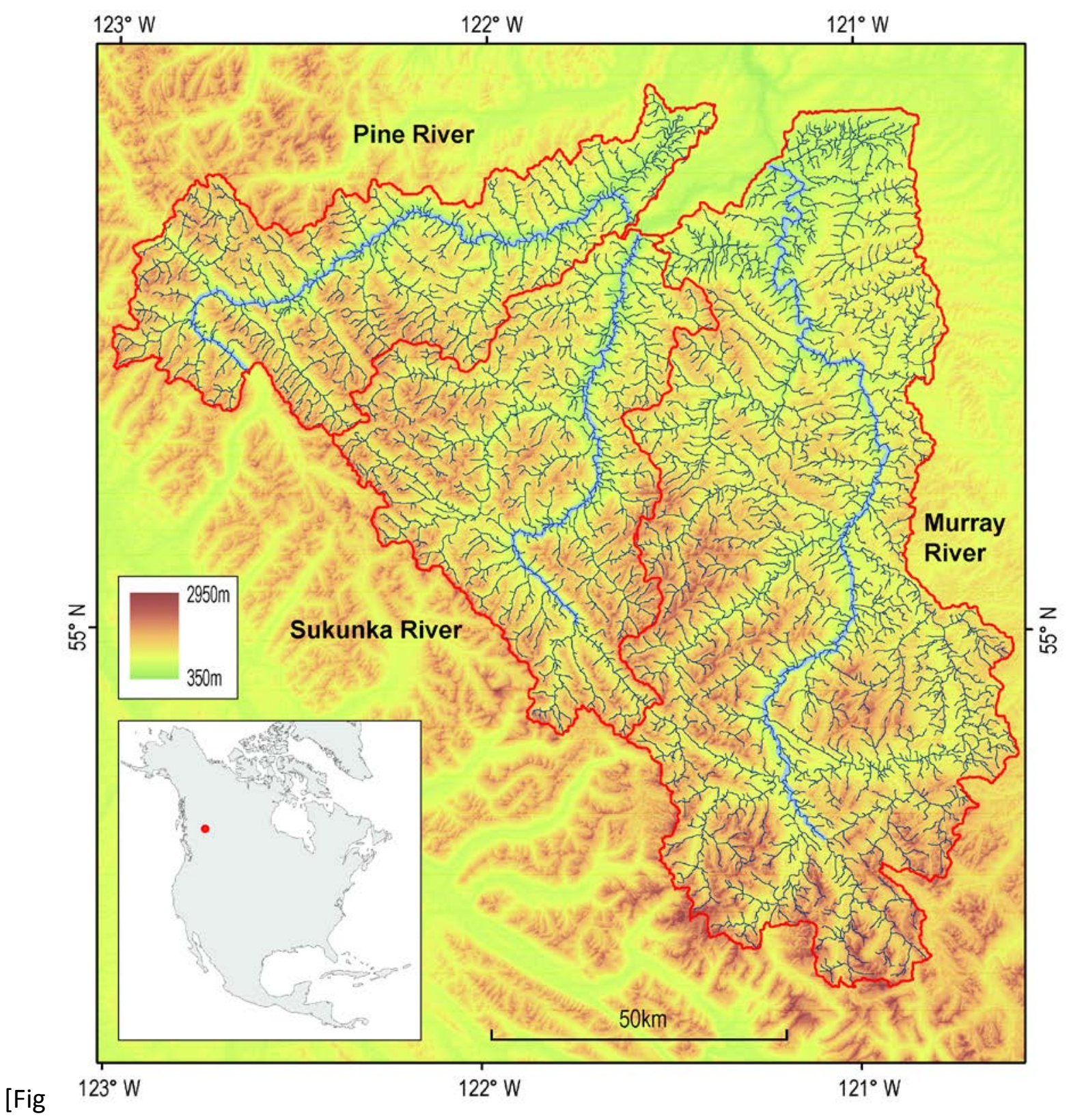

Figure 1 . Pine, Sukunka and Murray River basins and river networks determined by $D 8$ algorithm and pruned to match 1:50000 mapping. Inset shows location in British Columbia, Canada.

Aim 1 required automated extraction of the network and drainage basin characteristics necessary to derive the two independent variables used in equation 1 for the mainstem confluences of Sukunka River. This was achieved using RiverTools (v 2.4, Research Systems, Boulder USA) applied to mosaicked GeoBase digital elevation data tiles for the Sukunka catchment ( 0.75 arc-seconds or approximately $20 \mathrm{~m}$ resolution). For the whole Sukunka catchment, a flow grid was produced using the D8 algorithm with an improved imposedgradients routine to eliminate parallel flow paths on flat terrain. The river network was 
isolated and pruned until the derived network matched the blue-line network on 1:50000 National Topographic Survey of Canada mapping. RiverTools was then used to extract pertinent network and topographic properties for each of 1013 links in the network, including their length, gradient and upstream basin area as well as the magnitude, length and relief of the longest upstream chain. These link data were restructured using unique identifiers to produce a spreadsheet organised by confluences, from which 116 confluences along Sukunka mainstem were identified (Figure 1). In each case $A_{R}$ and $\psi_{t}$ were calculated from the derived data, using the slope of the tributary link connecting to the confluence as distal tributary slope, $S_{t}$. Equation 1 was then used to calculate $P_{D}$ for each mainstem confluence.

The expectation is that the automated method will have a similar performance to the manual method and correctly identify significant tributaries as significant (true positives) and incorrectly identify insignificant tributaries as significant (false positives) at similar rates to the manual method of Rice (1998). To make these comparisons, confluences with $P_{D}>0.8$ are regarded as those which have a high likelihood of tributary-driven aggradation. The choice of 0.8 is essentially arbitrary, driven by the need for some consistent criterion for making comparisons and the need to count as significant only those confluences that have a high probability of significance according to the logistic model. Higher values might exclude significant confluences and lower values might include insignificant confluences. In fact, the shape of the logisitic model, in which the curve flattens out at high probabilities, means that the criterion is quite insensitive to values in the range 0.7 to 1.0 . The performance of the automated method was assessed by examining whether confluences identified as significant using the automated method $\left(P_{D}>0.8\right)$ match those known to be significant from field evaluation and whether the rate of true and false positives are similar to those for the manual method (Rice, 1998).

Aims 2 and 3 required confluence data for networks which varied in shape, but where equation 1 might be expected to hold. Therefore, the networks of Pine and Murray Rivers, which are adjacent to Sukunka River, were extracted using the same process as for Sukunka River. For Pine and Sukunka, 17 fourth-order and independent third-order sub-networks were also identified (Figure 2). The Pine and Murray networks were pruned, as described above for Sukunka, using RiverTools. Low-order confluences were filtered out of this large 
data set because in small headwater streams hillslope coupling, bedrock and woody debris dominate sediment transfer processes so that tributary effects are likely to be indistinguishable from alternative sources of physical heterogeneity. Based on field observations of where such effects were dominant, confluences where the sum of the Strahler order of the upstream links was less than or equal to 3 , were excluded. This left a data set of 2028 ( $56 \%$ of the original) confluences across the three large basins.

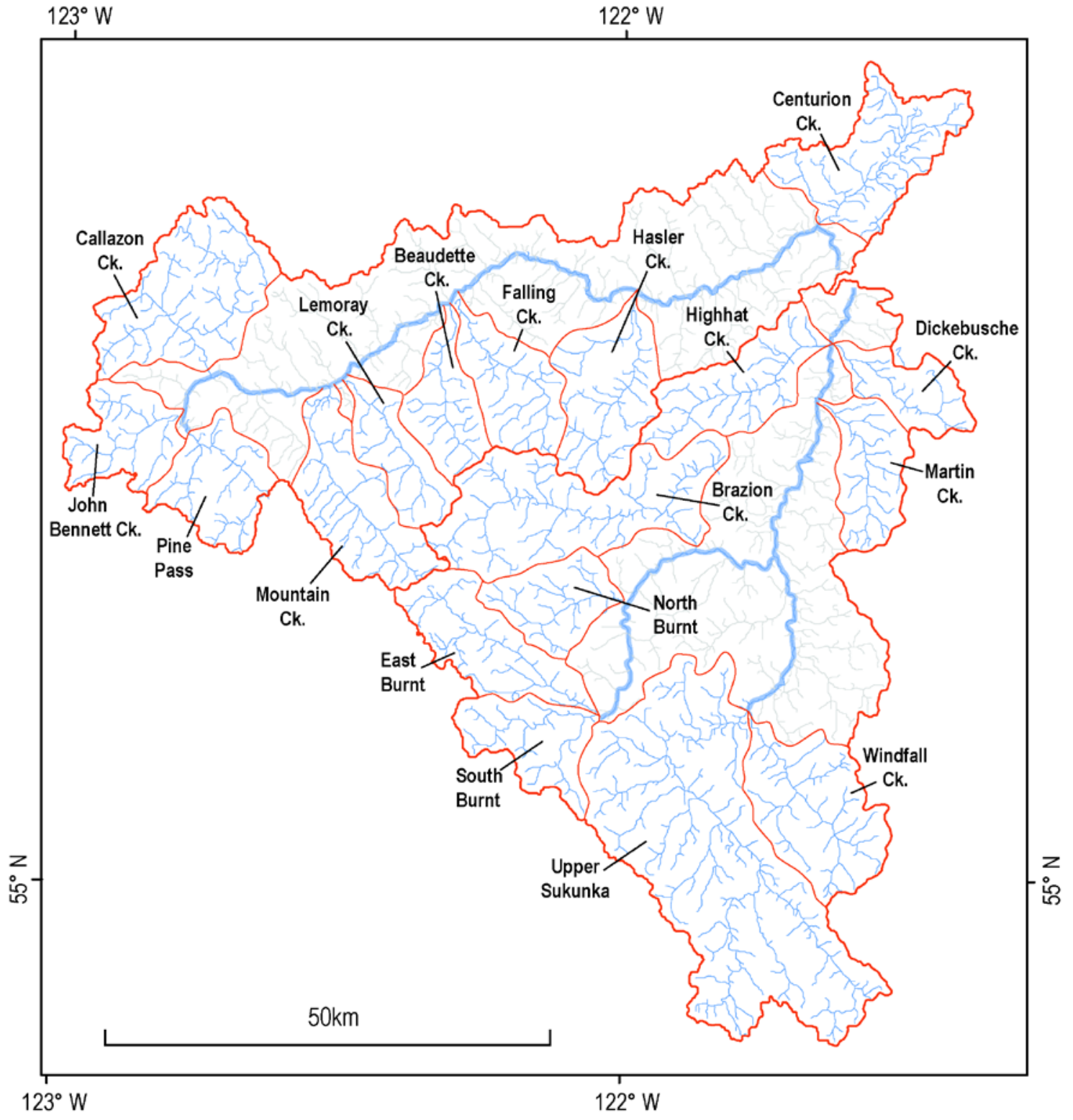

Figure 2. Pine and Sukunka catchments highlighting the 17 sub-basins utilised to examine relations between basin characteristics and the location and frequency of tributary-driven aggradation $t$ confluences 
In addition, one Pine tributary, Centurion Creek, occupies the former valley of the Pine River prior to the main stem's capture by Sukunka River probably during the Late Pleistocene. It is decidedly underfit (Dawson, 1881; Hughes, 1967), flows across the bed of a former glacial lake and rarely accesses coarse tributary deposits stored close to its valley walls. Centurion Creek was excluded because its topography and history are highly unusual compared with all of the other more mountainous sub-basins. RiverTools was used to extract tributary and mainstem basin properties for the remaining 1998 confluences as described above for the mainstem confluences on Sukunka River (Table 1).

The shape of each basin of interest (the three large basins, the combined basin formed above the confluence of Pine with Sukunka, and the 17 sub-basins within Pine and Sukunka) was quantified using:

$$
B=\frac{\sqrt{A}}{d}
$$

where $A$ is basin area $\left(\mathrm{km}^{2}\right)$ and $d$ is basin diameter $(\mathrm{km})$ defined as the maximum straightline distance between any two points on the basin perimeter. This metric is equivalent to the square root of the form factor (= A / $d^{2}$; Horton, 1932). Values of $B$ closer to 1.0 indicate more compact basins and smaller values more linear shapes. Evaluation of several shape metrics (including bifurcation ratio) showed that $B$ was most consistent in correctly differentiating basins that were visually categorised by the author as linear or compact.

The impact of basin shape on the longitudinal distribution of tributary-driven aggradation (aim 2) was assessed by examining downstream variations of $P_{D}$ in the 17 Pine and Sukunka sub-basins. Rather than selecting a single drainage line (e.g. the mainstem), the entire network was included. Confluence position was specified as the maximum distance to the head of a fingertip tributary, essentially distance downstream along the respective network branch. In addition to visualising the downstream pattern of $P_{D}$ values, the percentage of confluences with $P_{D}>0.8$ in the upstream (proximal) half of the mainstem length, $X(\%)$, was used as a metric to assess the expectation that in more linear basins a greater proportion of significant confluences would be concentrated upstream. The impact of size and shape on the magnitude of the cumulative, basin-wide, confluence effect (aim 3) was assessed by examining how the total number of confluences likely to be significant $\left(P_{D}>0.8\right)$ differed 
across the 17 sub-basins. To account for differences in basin size in the analysis of shape effects, the number of significant confluences $n$, was normalised by total channel length, $L$ :

$$
N=\frac{n_{0.8}}{L}
$$

The expectation was that more compact basins would yield a greater number of significant confluences per unit channel length. Values of $B$ varied between 0.48 and 0.70 for the 17 sub-basins (Table 1). For the purposes of testing hypothesised differences in $X$ and $N$ with shape, basins were placed into three groups according to which third of this distribution they belonged to: compact for $0.63<B<0.70$, linear for $0.48<B<0.55$, mixed for $0.55<B<$ 0.63. Simple t-tests were performed. 
Table 1. Basin and network characteristics for the 17 sub-basins and 3 large basins used in this study

\begin{tabular}{|c|c|c|c|c|c|c|c|}
\hline & Area $\left(\mathrm{km}^{2}\right)$ & $\begin{array}{c}\text { Strahler } \\
\text { order }\end{array}$ & $\begin{array}{c}\text { Drainage } \\
\text { density } \\
\left(\mathrm{km} \mathrm{km}^{-2}\right) \\
\end{array}$ & $\begin{array}{c}\text { Total } \\
\text { confluences }\end{array}$ & $\begin{array}{c}\text { Confluences } \\
\text { passing } \\
\text { coupling rule }\end{array}$ & Basin Shape & $\begin{array}{l}\text { Bifurcation } \\
\text { ratio }\end{array}$ \\
\hline Sukunka & 2894.6 & 6 & 0.742 & 804 & 469 & 0.620 & 4.020 \\
\hline North Burnt & 114.5 & 4 & 0.700 & 28 & 15 & 0.695 & 3.214 \\
\hline Dickebusch & 85.0 & 3 & 0.705 & 22 & 4 & 0.542 & 4.750 \\
\hline East Burnt & 165.7 & 4 & 0.703 & 40 & 22 & 0.482 & 3.519 \\
\hline Highhat & 157.6 & 4 & 0.827 & 56 & 29 & 0.503 & 4.456 \\
\hline Martin & 119.9 & 3 & 0.806 & 26 & 15 & 0.592 & 5.786 \\
\hline Brazion & 320.4 & 4 & 0.701 & 89 & 56 & 0.493 & 4.496 \\
\hline South Burnt & 127.2 & 4 & 0.682 & 29 & 17 & 0.573 & 3.500 \\
\hline Upper Sukunka & 697.16 & 4 & 0713 & 185 & 112 & 0.543 & 5.795 \\
\hline Windfall & 215.75 & 4 & 0.672 & 49 & 20 & 0.595 & 4.019 \\
\hline Pine & 2329.9 & 5 & 0.758 & 652 & 362 & 0.531 & 5.160 \\
\hline Falling & 132.6 & 4 & 0.736 & 32 & 19 & 0.570 & 3.375 \\
\hline Beaudette & 104.7 & 4 & 0.716 & 22 & 12 & 0.545 & 2.958 \\
\hline John Bennett & 91.8 & 4 & 0.704 & 26 & 16 & 0.482 & 3.119 \\
\hline Hasler & 193.5 & 4 & 0.710 & 51 & 24 & 0.613 & 3.844 \\
\hline Lemoray & 105.7 & 3 & 0.609 & 21 & 14 & 0.535 & 4.700 \\
\hline Mountain & 180.8 & 4 & 0.713 & 40 & 23 & 0.530 & 3.806 \\
\hline Callazon & 251.8 & 4 & 0.755 & 65 & 26 & 0.652 & 4.167 \\
\hline Pine Pass & 141.4 & 4 & 0.662 & 36 & 18 & 0.701 & 3.595 \\
\hline Pine+Sukunka & 5224.5 & 6 & 0.749 & 1456 & 831 & 0.589 & 4.700 \\
\hline Murray & 6471.7 & 6 & 0.836 & 2085 & 1167 & 0.529 & 4.784 \\
\hline
\end{tabular}




\section{RESULTS}

\subsection{Performance of the automated method}

Rice and Church (1998) identified 12 confluences on Sukunka mainstem as significant sediment sources with an impact on channel characteristics. Application of the logistic regression model (equation 1) using data derived from manual map-based measurements (Rice, 1998) correctly identified 11 of these (92\%) as 'significant', i.e. they had a predicted probability of impact exceeding 0.8 . By the same criterion, the automated method adopted here correctly identified 8 of the 12 (75\%) as significant. Of the insignificant confluences along Sukunka mainstem, $97.1 \%$ had $P_{D}<0.10$ and $100 \%$ had $P_{D}<0.80$ using the automated method, indicating a strong ability to correctly identify confluences with a low likelihood of mainstem impact.

Of the four misclassified significant cases: two nevertheless had high predicted probabilities of significance $\left(P_{D}=0.73\right.$ for Dickebusch Creek and $P_{D}=0.79$ for Baker/Lean-to Creek) so their misclassification reflects the choice of $P_{D}=0.8$ as a threshold, rather than a fundamental failing of the method; and one was the same tributary that the manual method failed to identify, which simply reflects the imperfection of the underlying discriminatory model. Of interest in the context of evaluating the automated method's performance, is significant tributary $\mathrm{S} 20$, which had $P_{D}=0.89$ using the manual method, but $P_{D}<0.001$ using the automated method. This is explained by assignment by the automated method of $S_{t}=$ 0.001 , which yields $\psi_{t}=0.04$, so that despite a relatively large symmetry ratio for this confluence (0.09), $P_{D}$ is small. St is small because in the extracted network the most distal tributary link is a short link that occurs on the valley flat and which is not indicative of the true potential for sediment supply from the tributary. This provides a good example of where automated methods can produce erroneous results. Basin topography may affect the propensity for this particular type of error to occur, but planimetric basin shape is unlikely to make such errors more or less likely, so that there is little likelihood that misclassification errors affect the primary goal here of assessing differences in confluence impacts between basins of different shape. 

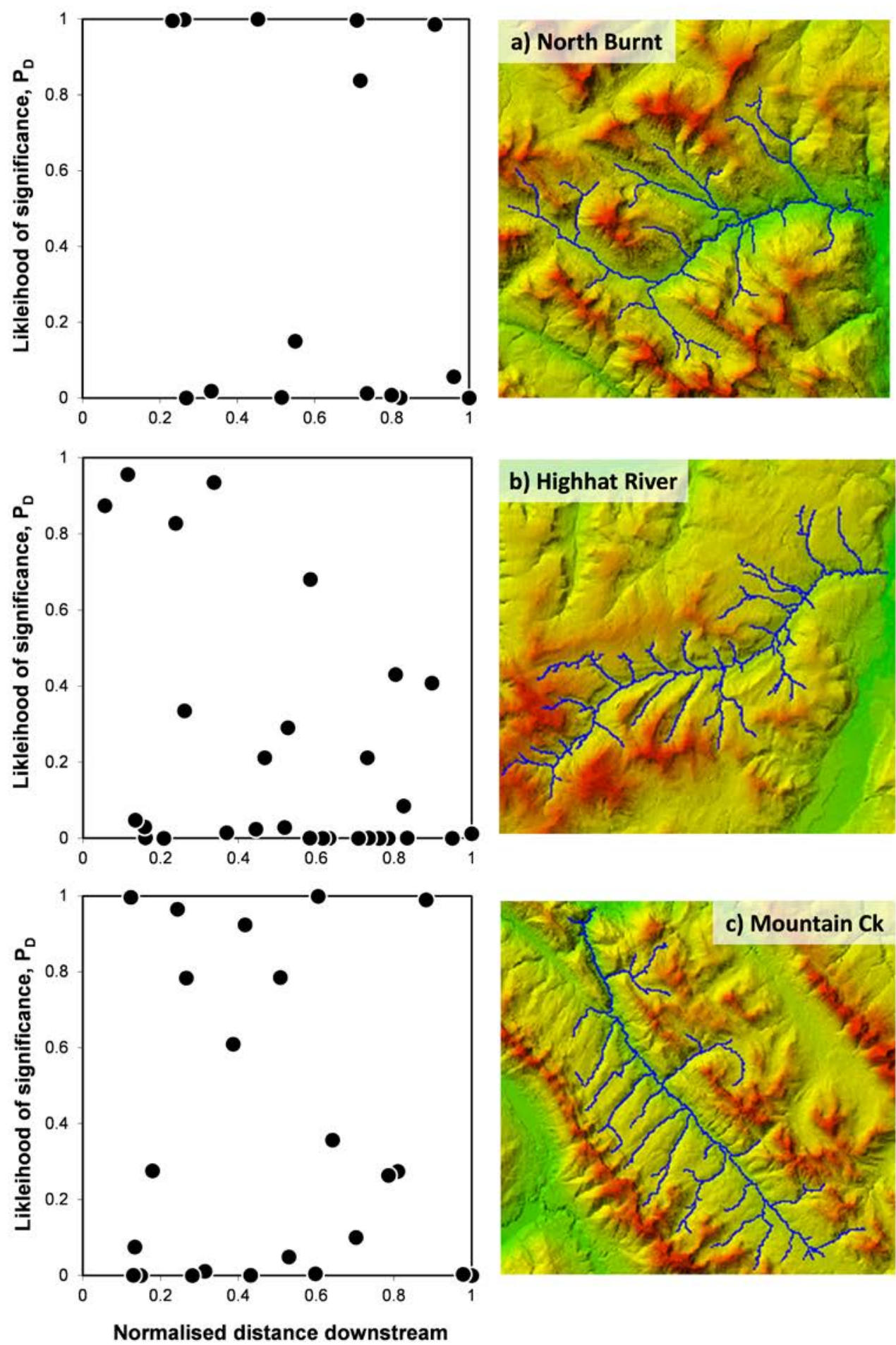

Figure 3. Three illustrations of typical patterns of downstream change in the probability of confluence significance $\left(P_{D}\right)$ : (a) North Burnt is characteristic of compact basins; (b) Highhat River is characteristic of linear basins; and (c) Mountain Creek exemplifies some linear basins where distal tributaries are sufficiently steep to generate aggradation despite small symmetry ratios. 


\subsection{Basin shape and downstream patterns of confluence impact}

Figure 3 provides three illustrative examples of how the likelihood of confluence significance (values of $P_{D}$ ) vary with distance downstream across the 17 pine and Sukunka sub-basins. For compact networks, for example in the Central Burnt basin (Figure 3a), the likelihood of tributary impact tends to stays high, as anticipated by Benda et al. (2004a) and Benda (2008), because there is a greater likelihood that a relatively large tributary can join the distal reach of any branch in the network. Some linear basins, for example Highhat River (Figure 3b), lack significant confluences in distal reaches, again as anticipated by Benda et al. (2004a) and Benda (2008). However, a number of linear basins, including Mountain Creek (Figure 3c) do not follow the expected pattern with significant confluences close to their outlets.

For the complete set of 17 sub-basins, the proportion of significant confluences $\left(P_{D}>0.8\right)$ that occur in the upstream $50 \%$ of each network $X$, declined as basin shape $B$, tended toward more compact (Figure 4a) and although the negative correlation between the two variables was not significant at $\alpha=0.05\left(r_{(15)}=-0.45, p=0.07\right)$, mean proximity for the linear basins $(X=67, \mathrm{SD}=17.5)$ was significantly greater (Figure $\left.4 \mathrm{~b} ; \mathrm{t}_{(10)}=2.01, p=0.04\right)$ than for the compact basins $(X=44.5, \mathrm{SD}=19.9)$.
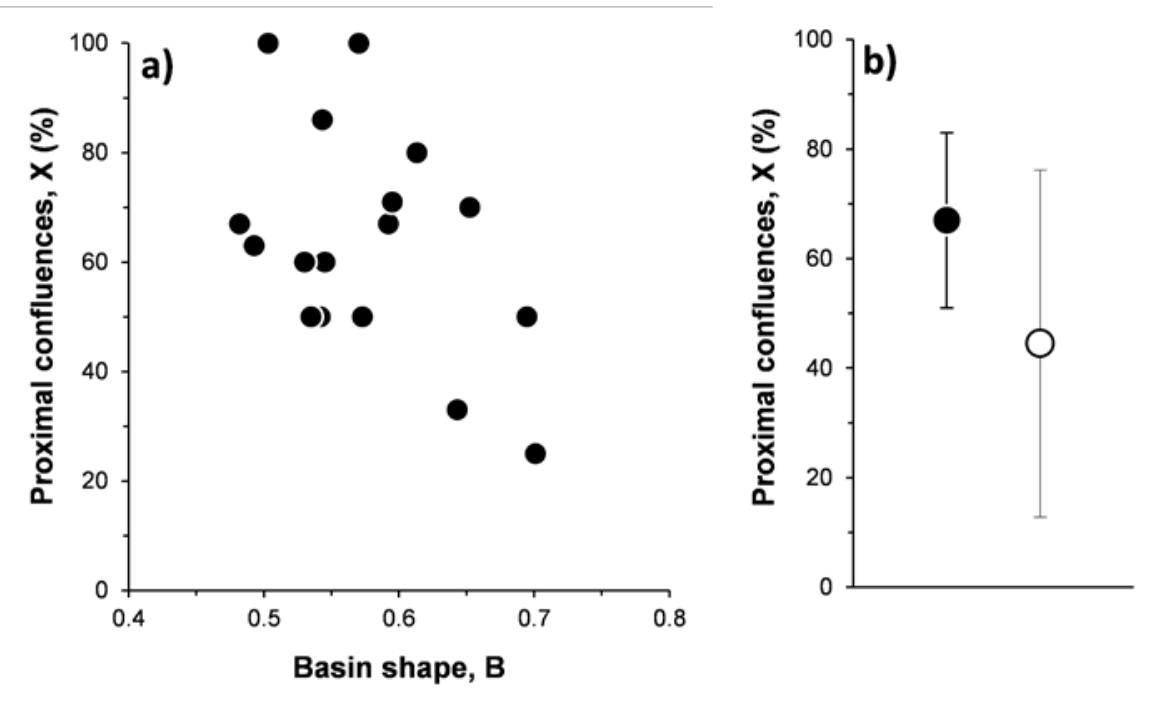

Figure 4. (a) Percentage of significant confluences $\left(P_{D}>0.8\right)$ in the proximal (upstream) half of each sub-basin $X$, plotted against subbasin shape, $B$. (b) Comparison of mean $X$, with $95 \%$ confidence intervals, for sub-basins in the compact (open circle; $0.63<B<0.70$ ) and linear (solid circle; $0.48<B<0.55$ ) groups. 


\subsection{Basin size, shape and the frequency distribution of confluence impact probabilities}

The number of significant $\left(P_{D}>0.8\right)$ confluences $n_{0.8}$, increases with total network length $L$ (Figure 5) and simple linear regression yields the following significant relation across the full range of basin scales (the three large basins and the 17 sub-basins):

$$
n=0.066 L^{0.893}\left(\mathrm{R}^{2}=0.95, \mathrm{~F}_{(1,18)}=314.9, \mathrm{p}<0.001\right)
$$

Drainage area and network length are strongly correlated $\left(r_{(18)}=0.99, p<0.001\right)$ and an equivalent using $A$ is:

$$
n=0.042 A^{0.920}\left(\mathrm{R} 2=0.95, \mathrm{~F}_{(1,18)}=317.0, \mathrm{p}<0.001\right)
$$

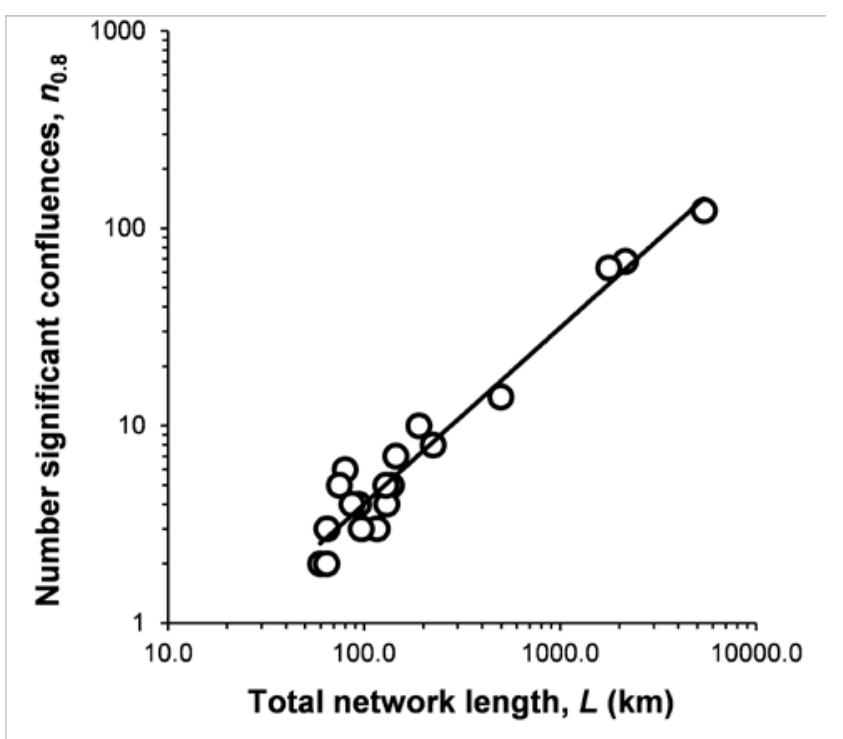

Figure 5. Relation between total channel length $L(\mathrm{~km})$, and the number of significant confluences $n_{0.8}$ in the 17 sub-basins and three large basins. The plotted line is described by equation 5 and was fitted using least squares linear regression.

The number of significant confluences per unit channel length $N$, increased as basin shape $B$, tended toward more compact (Figure 6a) and there was a significant $(\alpha=0.05)$ positive correlation between the two variables; $r_{(17)}=0.59, p=0.01$. Also, mean $N$ for linear basins $(N=0.036, \mathrm{SD}=0.013)$ was significantly less (Figure $6 \mathrm{~b} ; \mathrm{t}_{(10)}=2.16, p=0.03$ ) than for compact basins $(N=0.054, \mathrm{SD}=0.014)$. 

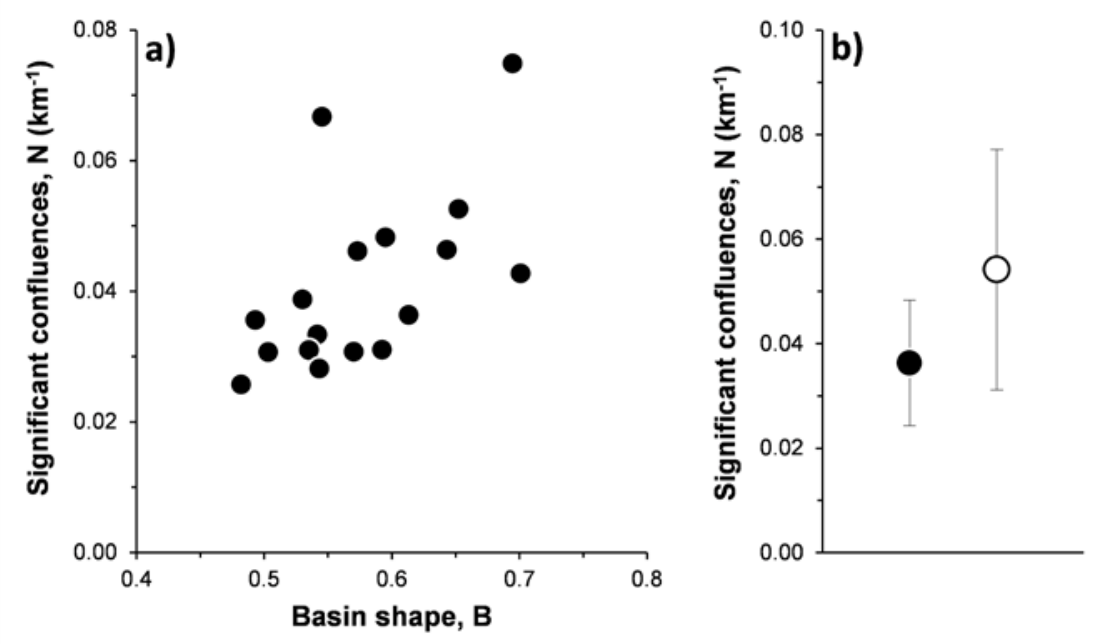

Figure 6. (a) Number of significant confluences $\left(P_{D}>0.8\right)$ per unit channel length $N\left(\mathrm{~km}^{-1}\right)$, plotted against sub-basin shape, $B$. (b) Comparison of mean $N$, with $95 \%$ confidence intervals, for sub-basins in the compact (open circle; $0.63<B<0.70$ ) and linear (solid circle; $0.48<B<0.55)$ groups.

\section{DISCUSSION}

In a systematic test of an automated method for identifying tributary significance, using a criterion for significance of $P_{D}>0.8$, insignificant confluences were never misclassified as significant, but $25 \%$ of significant tributaries were misclassified as insignificant. Only 1 of 4 misclassifications was caused by errors introduced by the automated method. The success rate of $75 \%$ (or $83 \%$ if the significance criterion is reduced to $P_{D}=0.70$ ) compared with $93 \%$ for the equivalent manual method, suggests that the automated method provided an adequate means of deriving predictions of confluence significance. However, it is safe to suggest that the predictions of significance made herein are conservative and may underestimate the true population of significant confluences by one third. In general, this highlights how difficult it is to predict tributary impacts using simple algorithms that use basin-scale characteristics as surrogates for the key controls of tributary impact: relative bedload flux, grains size and discharge.

Nevertheless, empirical analysis of confluence significance across the study area confirmed expectations (Benda et al., 2004a; Benda, 2008) that the number of significant confluences increases with total network length and drainage area. The relation between $n_{0.8}$ and $A$ 
(equation 6) suggests an eight-fold increase in the number of significant confluences for a ten-fold increase in basin area, or a 1.9-fold increase in significant confluences for a doubling of basin area. Also as anticipated by Benda et al. (2004a) and Benda (2008), basin shape was a strong control of both the number of significant confluences and their spatial distribution: relatively compact basins tended to host a greater number of significant confluences and those confluences were more likely to be distributed across the network. In contrast, relatively linear basins were more likely to have fewer aggradational confluences that were concentrated in proximal reaches. Figure 6a suggests that, on average, the most compact basins in the study area $(B \approx 0.70)$ contained approximately twice as many significant confluences per kilometre of channel as the most linear basins $(B \approx 0.48$ ).

The relation between basin shape and the downstream distribution of significant confluences, did not match the expectation in every case, with significant tributaries in the distal portions of several linear basins. This reflects the key difference in Rice's (1998) predictive equation, which was used here, compared with Benda et al.'s (2004a) model. While the latter uses symmetry ratio as the only independent parameter, Rice's model includes a bedload supply parameter that is proportional to tributary slope (equation 1). Some of the linear basins encountered here are predicted to have distal tributaries that are important for aggradation, even though symmetry ratios are relatively small, because those tributaries are steep. This may reflect the physiography of the mountainous terrain of these Rocky Mountain foothill rivers. The major trunk streams (Pine, Sukunka, Murray) sit in relatively wide, flat alluvial valleys but receive water and sediment from steeper tributaries that lack strong alluvial development and, themselves, are supplied by streams draining steep, mountainous terrain. In linear basins it is therefore possible that distal tributaries, although small, are steep with the potential to supply large quantities of coarse sediment that forces aggradation.

These results matter for sediment connectivity, because tributary-driven aggradation at confluences interrupts the sediment cascade, promotes sediment storage on various timescales and is associated with the modification or 'resetting' of key mainstem parameters that define river form and functions (available grain size, bedload flux, channel slope and in some cases available discharge too). Aggradational confluence locations are therefore likely to be sites of morphological adjustment and longitudinal change, which 
along with other controls on sediment supply, transfer and deposition (e.g. structural, lithological, hydroclimatic and anthropogenic effects) define network-scale patterns of sediment connectivity and channel morphology. While these other factors vary in their importance from basin to basin, all river networks contain confluences such that confluence aggradation and the associated sedimentary links are ubiquitous controls that structure the operation and morphology of river channels.

Moreover, increased physical heterogeneity produced by tributary-driven aggradation is a source of potentially important habitat heterogeneity in river ecosystems (Benda et al., 2004b; Benda, 2008; Rice et al., 2001; 2008). Confluences are important ecological elements for a number of other reasons too and there is broad recognition amongst ecologists that understanding confluence, link and networks effects is essential for improving understanding of the spatial and temporal distribution of river organisms and the collective health of river ecosystems (Davey and Lapointe, 2007; Poole 2002; Benda et al., 2004b; Thorp et al., 2006; Grant et al., 2007; Widder et al., 2014; Thorp, 2014; Erös and Grant, 2015; Lanthier et al. 2015; Hauer 2015). The simple relations identified here, between the frequency and likelihood of tributary-driven aggradation and basin shape and size, support Benda's Network Dynamics Hypothesis (Benda et al., 2004b). In combination with Rice et al.'s (2001) Link Discontinuity Concept, this suggests that compact shaped basins are more likely to contain drainage lines with repeated shifts from relatively low-gradient, low Froude reaches with finer bed materials (upstream of significant confluences, at the distal end of sedimentary links) to higher gradient, higher Froude reaches with coarser, but fining, bed materials (downstream of significant confluences at the proximal end of sedimentary links). In turn, to the extent that physical heterogeneity matters for biodiversity and ecosystem health, the cumulative ecological benefit of tributary-driven aggradation should be greater in more compact basins; a hypothesis that remains to be tested.

Given the potential geomorphological and ecological value in being able to identify the location, number and distribution of significant confluences, but the limited ability of simple models like the one used here to successfully identify all of them, it is appropriate to consider alternative methods. Numerous distributed numerical models of sediment transfer through river networks (Gasparini et al., 1999; Sklar et al., 2006; Lewicki et al., 2007; Neupane and Yager, 2013; Gran and Czuba, this volume) or across landscapes (Gasparini et 
al., 2004, 2008; van Balen et al., 2010; Coulthard and Van de Wiel, 2012) include spatially explicit, time-dependent adjustment of bed material grain size and bed elevation that could be used to detect confluence aggradation. Czuba and Foufoula-Georgiou (2015) have recently offered a numerical modelling framework for identifying places of excess sediment accumulation ("clusters") in river networks. Such models are applicable to the problem of predicting the location of tributary-driven aggradation, but to date none of them have been used to explicitly address this question. This is an area where fruitful progress might be made.

Similarly, remote sensing technologies are making it increasingly feasible to collect information about rivercapes (Fausch et al., 2002) at network scales (Marcus and Fonstad, 2008; Hugue et al., 2016) and new analytical tools are being developed to make maximum use of that ability (e.g. Fonstad and Marcus, 2010). Early progress toward automated estimation of bed material grain size at bar-scales (Chandler et al., 2004; Verdu et al., 2005) and along entire rivers (Carbonneau et al., 2004, 2005) has been extended by using imagery to accomplish the necessary grain-size calibration (Dugdale et al., 2010), by avoiding the need for calibration at all (Buscombe and Masselink, 2009; Buscombe et al., 2010) and by using hyperspatial data ( $<100 \mathrm{~mm}$ resolution) to map sub-pixel grain sizes (Black et al., 2014). These advances mean that it is feasible to aquire continuous bed material grain size information and identify tributary-driven confluence aggradation and sedimentary links at network scales (Fonstad and Marcus, 2010). While such an approach is currently not a routine undertaking, it could provide data for testing the ideas presented here and, in due course, mapping of grain size and might become a straightforward means of mapping local heterogeneity across whole networks.

\section{CONCLUSION}

An automated process for establishing the likelihood of confluence impact on bed material grain size provided a means to examine the likely impact of tributaries on channel aggradation and hence morphological and habitat diversity at over 3500 confluences, across three large drainage basins with a total area of approximately $11700 \mathrm{~km}^{2}$. Contrasting subbasin sizes and shapes allowed empirical evaluation of several hypotheses surrounding 
basin-scale controls on the number and distribution of significant confluences (Benda, 2008). As anticipated, significant confluences were found to be more abundant in larger basins and compact basins tended to host a greater number of significant confluences, which were more likely to be distributed across the network. In some linear basins, distal tributaries were associated with significant aggradation because their steepness and therefore potential for coarse sediment delivery compensated for relatively small size. The most compact basins contained approximately twice as many significant confluences per unit channel length as the most linear basins. These results are important, because they suggest that differences in basin size and shape, via impacts on the amount and distribution of tributary-driven confluence aggradation, are key controls of coarse-sediment connectivity and habitat heterogeneity in river networks. To the extent that physical heterogeneity matters for biodiversity, this has implications for cumulative ecosystem health, with potentially greater aquatic biodiversity in compact basins; a hypothesis that remains to be tested. 


\section{REFERENCES}

Al Farraj, A., Harvey, A., 2010. Influence of hillslope-to-channel and tributary-junction coupling on channel morphology and sediments: Bowderdale Beck, Howgill Fells, NW England. Zeitschrift für Geomorphologie 54, 203-224.

Benda, L.E., 2008. Confluence Environments at the Scale of River Networks. In Rice. S.P., Roy A.G., Rhoad, B.L. (Eds), River confluences, Tributaries and the Fluvial Network. John Wiley and Sons, Chichester, 271-300.

Benda, L.E., Cundy, T.W., 1990. Predicting deposition of debris flows in mountain channels. Canadian Geotechnical Journal 27, 409-417.

Benda, L., Dunne, T., 1997. Stochastic forcing of sediment routing and storage in channel networks. Water Resources Research 33, 2865-2880.

Benda, L., Andras, K., Miller, D., Bigelow, P., 2004a. Confluence effects in rivers: interactions of basin scale, network geometry, and disturbance regimes. Water Resources Research 40, W05402.

Benda, L., Poff, N.L., Miller, D., Dunne, T., Reeves, G., Pess, G., Pollock, M., 2004b. The Network Dynamics Hypothesis: How channel networks structure riverine habitats.

BioScience 54, 413-427.

Besemer, K., Singer, G., Quince, C., Bertuzzo, E., Sloan, W., Battin, T.J., 2013. Headwaters are critical reservoirs of microbial diversity for fluvial networks. Proceedings Royal Society B 280, 2013.1760 .

Black, M., Carbonneau, P., Church, M. Warburton, J., 2014. Mapping sub-pixel fluvial grain sizes with hyperspatial imagery. Sedimentology 61, 691-711

Brierley, G.J., Fryirs, K., 1999. Tributary-trunk stream relations in a cut and-fill landscape: a case study from Wolumla catchment, N.S.W., Australia. Geomorphology 28, 61-73.

Buscombe, D., Masselink, G., 2009. Grain size information from the statistical properties of digital images of sediment. Sedimentology 56, 421-438. 
Buscombe, D., Rubin, D.M. and Warrick, J.A., 2010. A universal approximation of grain size from images of noncohesive sediment. Journal of Geophysical Research 115, F02015.

Cairns, M.A., Ebersole, J.L., Baker, J.P., Wigington, P.J., Lavigne, H.R., Davis, J.A., 2005. Influence of summer stream temperatures on black spot infestation of juvenile Coho salmon in the Oregon Coast Range. Transactions of the American Fisheries Society 134, 1471-1479.

Carbonneau, P.E., Lane, S.N., Bergeron, N.E., 2004. Catchment-scale mapping of surface grain size in gravel bed rivers using airborne digital imagery. Water Resources Research 40, W07202.

Carbonneau, P.E., Bergeron, N.E., Lane, S.N., 2005. Automated grain size measurements from airborne remote sensing for long profi le measurements of fluvial grain sizes. Water Resources Research 41, W11426.

Chandler, J. H., Rice, S. and Church, M., 2004. Colour aerial photography for riverbed classification, The International Archives of the Photogrammetry. Remote Sens. Spatial Inform. Sci., 34, Commission 7, Istanbul, 1079-1085. Available at: http://www.isprs.org/proceedings /XXXV/congress/comm7/papers/206.pdf

Church, M., Kellerhals, R., 1978. On the statistics of grain size variation along a gravel river. Canadian Journal of Earth Science 15, 1151-1160.

Clay, P.A., Muehlbauer, J.D., Doyle, M.W., 2015. Effect of tributary and braided confluences on aquatic macroinvertebrate communities and geomorphology in an alpine river watershed. Freshwater Science 34, 845-856.

Coulthard, T.J. and Van De Wiel, M.J., 2012. Modelling river history and evolution, Philosophical Transactions Royal Society A 370, 2123-2142.

Czeglédi, I., Sály, P., Takács, P., Dolezsai, A., Nagy, S.A., Erös, T., 2015. The scales of variability of stream fish assemblages at tributary confluences. Aquatic Sciences, DOI 10.1007/s00027-015-0454-z.

Czuba, J.A., Foufoula-Georgiou, E., 2015. Dynamic connectivity in a fluvial network for identifying hotspots of geomorphic change. Water Resources Research 51, 1401-1421. 
Davey C., Lapointe M., 2007. Sedimentary links and the spatial organization of Atlantic salmon (Salmo salar) spawning habitat in a Canadian Shield river. Geomorphology 83, 8296.

Dawson, G.M., 1881. Report on the exploration from Port Simpson on th pacific Coast, to Edmonton on the Seskatchewan, embracing a portion of the northern part of British Columbia and the Peace River country 1879. Geological Survey of Canada, Report of Progress, 1879-1880 (part B), 142 pp.

Dugdale S.J., Carbonneau P.E., Campbell D., 2010. Aerial photosieving of exposed gravel bars for the rapid calibration of airborne grain size maps. Earth Surface Processes and Landforms 35, 627-639.

Erös, T., Grant, E.H.C., 2015. Unifying research on the fragmentation of terrestrial and aquatic habitats: patches, connectivity and the matrix in riverscapes. Freshwater Biology 60, $1487-1501$.

Fausch, K.D., Torgersen, C.E., Baxter, C.V., Li, H.W., 2002. Landscapes to riverscapes: bridging the gap between research and conservation of stream fishes. Bioscience 52, 483498.

Ferguson, R.I., Hoey, T.B., 2008. “Effects of tributaries on main-channel geomorphology". In Rice. S.P., Roy A.G., Rhoad, B.L. (Eds), River confluences, Tributaries and the Fluvial Network. John Wiley and Sons, Chichester, 183-208.

Ferguson, R.I., Cudden, J.R., Hoey, T.B., Rice, S.P., 2006. River system discontinuities due to lateral inputs: generic styles and controls. Earth Surface Processes and Landforms 31, 11491166.

Fernandes, C.C., Podos, J., Lundberg, J.G., 2004. Amazonian ecology: Tributaries enhance the diversity of electric fishes. Science 305, 1960-1962.

Fonstad, M.A., Marcus, W.A., 2010. High resolution, basin extent observations and implications for understanding river form and process. Earth Surface Processes and Landforms 35, 680-698. 
Franks, C.A., Rice, S.P., Woods, P.J., 2002. Hydraulic habitat in confluences: an ecological perspective on confluence hydraulics. In Dyer, F.J., Thoms, M.C., Olley, J.M. (Eds), The Structure, Function and Management Implications of Fluvial Sedimentary Systems, IAHS publication no 276, International Association of Hydrological Sciences, 61-67.

Fraser, D.F., Gilliam, J.F., Yip-Hoi, T., 1995. Predation as an agent of population fragmentation in a tropical watershed. Ecology 76, 1461-1472.

Fryirs, K., Brierley, G.J., Preston, N.J., Kasai, M., 2007. Buffers, barriers and blankets: the (dis)connectivity of catchment-scale sediment cascades. Catena 70, 49-67.

Fryirs, K., 2013. (Dis)Connectivity in catchment sediment cascades: a fresh look at the sediment delivery problem. Earth Surface Processes and Landforms 38, 30-46.

Gasparini, N.M., Tucker, G.E., Bras, R.L., 1999. Downstream fining through selective particle sorting in an equilibrium drainage network. Geology 27, 1079-1082.

Gasparini, N.M., Tucker, G.E., Bras, R.L., 2004. Network-scale dynamics of grain-size sorting: implications for downstream fining, stream-profile concavity, and drainage basin morphology. Earth Surface Processes and Landforms 29, 401-421.

Gasparini, N.M., Bras, R.L., Tucker, G.E., 2008. Numerical predictions of the sensitivity of grain size and channel slope to an increase in precipitation. In Rice. S.P., Roy A.G., Rhoad, B.L. (Eds), River confluences, Tributaries and the Fluvial Network. John Wiley and Sons, Chichester, 367-394.

Gran, K.B., Czuba, J.A., (in review, this volume) Sediment pulse evolution and the role of network structure. Geomorphology.

Grant, E.H.C., Lowe, W.H., Fagan, W.F., 2007. Living in the branches: population dynamics and ecological processes in dendritic networks. Ecology Letters 10, 165-175.

Hanks, T.C., Webb, R.H., 2006. Effects of tributary debris on the longitudinal profile of the Colorado River in Grand Canyon. Journal of Geophysical Research (Earth Surface) 111, F02020. 
Harmar, O.P., Clifford, N.J., 2006. Planform dynamics of the Lower Mississippi River. Earth Surface Processes and Landforms 31, 825-843.

Horton, R.E., 1932. Drainage basin characteristics. Transactions of the American Geophysical Union, 13, 350-61.

Hughes, J.E., 1967. Geology of the Pine valley: Mount Wabi to Solitude Mountain, northeastern British Columbia. BC Department of Mineral and Petroleum Resources Bulletin 52, $137 p p$.

Hauer, C. 2015. Review of hydro-morphological management criteria on a river basin scale for preservation and restoration of freshwater pearl mussel habitats. Limnologica 50, 40-53.

Hugue, F., Lapointe, M., Eaton, B.C., Lepoutre, A., 2016. Satellite-based remote sensing of running water habitats at large riverscape scales: Tools to analyze habitat heterogeneity for river ecosystem management. Geomorphology 253, 353-369.

Kasai, M., Brierley, G.J., Pahe, M.J., Marutani, T., Trustrum, N.A., 2005. Impacts of land use change on patterns of sediment flux in Weraamaia catchment, New Zealand. Catena 64, 2760.

Katano, I., Negishi, J.N., Minagawa, T., Doi, H., Kawaguchi, Y., 2009. Longitudinal macroinvertebrate organization over contrasting discontinuities: effects of a dam and a tributary. Journal of the North American Benthological Society 28, 331-351.

Kiffney, P.M., Greene, C., Hall, J., Davies, J., 2006. Gradients in habitat heterogeneity, productivity, and diversity at tributary junctions. Canadian Journal of Fisheries and Aquatic Sciences 63, 2518-2530.

Knighton, A.D., 1980. Longitudinal changes in size and sorting of stream-bed material in four English rivers. Geological Society of America Bulletin 91, 55-62.

Knighton, A.D., 1989. River adjustment to changes in sediment load: the effects of tin mining on the Ringarooma River, Tasmania, 1875-1984. Earth Surface Processes and Landforms 14, 333-359. 
Knispel, S., Castella, E., 2003. Disruption of a longitudinal pattern in environmental factors and benthic fauna by a glacial tributary. Freshwater Biology 48, 604-618.

Kreb, D., Budiono, Y.K., 2005. Conservation management of small core areas: key to survival of a critically endangered population of Irrawaddy river dolphins Orcaella brevirostris in Indonesia. Oryx 39, 178-188.

Krumbein, W.C., 1942. Flood deposits of the Arroyo Seco, Los Angeles County, California. Geological Society of America Bulletin 53, 1355-1402.

Kupferberg, S.J., 1996. Hydrologic and geomorphic factors affecting conservation of a riverbreeding frog (Rana boylii). Ecological Applications 6, 1332-1344.

Kuo, G-W., Brierley, G.J., 2014. The influence of landscape configuration upon patterns of sediment storage in a highly connected river system. Geomorphology 180-181, 255-266.

Lane, E.W., 1955. The importance of fluvial morphology in hydraulic engineering. Journal of the Hydraulics Division ASCE 81, 1-17.

Lanthier, G., Bédard, M-E., Lapointe, M., Boisclair, D., 2015. Assessment of the structural role of sedimentary links on the spatial distribution of periphyton and fish in a Canadian Shield river. Aquatic Sciences 77, 141-152.

Lewicki, M., Pizzuto, J.E., Moglen, G.E., Allmendinger, N.E., 2007. A watershed scale numerical model of the impact of land use change on bed material transport in suburban Maryland, USA. Water Resources Research, 43, W07424.

Marcus, W.A., Fonstad, M.A., 2008. Optical remote mapping of rivers at sub-meter resolutions and watershed extents. Earth Surface Processes and Landforms 33, 4-24.

McEwen, L.J., Miller, J.A., 1998. Channel form, bed material and sediment sources of the Sprongdøla, southern Norway; evidence for a distinct periglacio-fluvial system. Geografiska Annaler 80A, 17-35.

Menting, F., Langston, A.L., Temme, A.J.A.M., 2015. Downstream fining, selective transport, and hillslope influence on channel bed sediment in mountain streams, Colorado Front Range, USA. Geomorphology 239, 91-105. 
Milesi, S.V., Melo, A.S., 2014. Conditional effects of aquatic insects of small tributaries on mainstream assemblages: position within drainage network matters. Canadian Journal of Fisheries and Aquatic Sciences 71, 1-9.

Miller, J.P., 1958. High mountain streams: effects of geology on channel characteristics and bed material. Memoir 4, State Bureau of Mines and Mineral Resources, New Mexico Institute of Mines and Mining Technology: Socorro, New Mexico.

Mosley, M.P., 1976. An experimental study of channel confluences. Journal of Geology 84, 535-562.

Mosley, M.P., Schumm, S.A., 2001. Gravel-bed rivers - the view from the hills. In Mosley, M.P. (Ed) Gravel bed Rivers V. New Zealand Hydrological Society: Wellington, New Zealand, 479-505

Nakamoto, R.J., 1994. Characteristics of pools used by adult summer steelhead oversummering in the New-River, California. Transactions of the American Fisheries Society $123,757-765$.

Neupane, S., Yager, E.M., 2013. Numerical simulation of the impact of sediment supply and streamflow variations on channel grain sizes and Chinook salmon habitat in mountain drainage networks. Earth Surface Processes and Landforms 38, 1822-1837.

Poole G.C., 2002. Fluvial landscape ecology: addressing uniqueness within the river discontinuum. Freshwater Biology 47, 641-660.

Power, M.E., Dietrich, W.E., 2002. Food webs in river networks. Ecological Research 17, 451471.

Rengers, F., Wohl, E., 2007. Trends of grain sizes on gravel bars in the Rio Chagres, Panama. Geomorphology 83, 282-293.

Rhoads, B.L., 1987. Changes in stream channel characteristics at tributary junctions. Physical Geography 8, 346-361.

Rice, S.P., 1998. Which tributaries disrupt downstream fining along gravel-bed rivers? Geomorphology 22, 39-56. 
Rice, S.P., 1999. The nature and controls of downstream fining within sedimentary links. Journal of Sedimentary Research 69, 32-39.

Rice, S.P., Church, M., 1996. Bed material texture in low order streams on the Queen Charlotte Islands, British Columbia. Earth Surface Processes and Landforms 21, 1-18.

Rice, S.P., Church, M., 1998. Grain size along two gravel-bed rivers: statistical variation, spatial pattern and sedimentary links. Earth Surface Processes and Landforms 23, 345-363.

Rice, S.P., Church, M.. 2001. Longitudinal profiles in simple alluvial systems. Water Resources Research 37, 417-426.

Rice, S.P., Greenwood, M.T., Joyce, C.B., 2001. Tributaries, sediment sources and the longitudinal organisation of macroinvertebrate fauna along river systems. Canadian Journal of Fisheries and Aquatic Sciences 58, 824-840.

Rice, S.P., Ferguson, R.I., Hoey, T.B., 2006. Tributary control of physical heterogeneity and biological diversity at river confluences. Canadian Journal of Fisheries and Aquatic Sciences $63,2553-2566$.

Rice, S.P., Kiffney, P., Greene, C. Pess, G.R., 2008. The ecological importance of tributaries and confluences. In Rice. S.P., Roy A.G., Rhoad, B.L. (Eds), River confluences, Tributaries and the Fluvial Network. John Wiley and Sons, Chichester, 209-242.

Scrivener, J.C., Brown, T.G., Andersen, B.C., 1994. Juvenile Chinook Salmon (OncorhynchusTshawytscha) utilization of Hawks Creek, a small and nonnatal tributary of the Upper FraserRiver. Canadian Journal of Fisheries and Aquatic Sciences 51, 1139-1146.

Singer, M.B., 2008. Downstream patterns of bed material grain size in a large, lowland alluvial river subject to low sediment supply. Water Resources Research 44, W12202, doi:10.1029/2008WR007183.

Sklar, L.S., Dietrich, W.E., Foufoula-Georgiou, E., Lashermes, B., Bellugi, D., 2006. Do gravel bed river size distributions record channel network structure? Water Resources Research 42, W06D18. 
Swanson, B.J., Meyer, G., 2014. Tributary confluences and discontinuities in channel form and sediment texture: Rio Chama, NM. Earth Surface Processes Landforms 39, 1927-1943.

Taverny, C., Lassalle, G., Ortusi, I., Roqueplo, C., Lepage, M., Lambert, P., 2012. From shallow to deep waters: habitats used by larval lampreys (genus Petromyzon and Lampetra) over a western European basin. Ecology of Freshwater Fish 21, 87-99.

Thornbrugh, D.J., Gido, K.B., 2010. Influence of spatial positioning within stream networks on fish assemblage structure in the Kansas River basin, USA. Canadian Journal of Fisheries and Aquatic Sciences 67, 143-156.

Thorp, J.H., Thoms, M.C., Delong, M.D., 2006. The riverine ecosystem synthesis: biocomplexity in river networks across space and time. River Research and Applications 22, 123-147.

Thorp, J.H., 2014. Metamorphosis in river ecology: from reaches to macrosystems. Freshwater Biology 59, 200-210.

Torgersen, C.E., Gresswell, R.E., Bateman, D.S., Burnett, K.M., 2008. Spatial Identification of tributary impacts in river networks. In Rice. S.P., Roy A.G., Rhoad, B.L. (Eds), River confluences, Tributaries and the Fluvial Network. John Wiley and Sons, Chichester, 159-181.

Van Balen, R.T., Busschers, F.S., Tucker, G.E., 2010. Modeling the response of the RhineMeuse fluvial system to Late Pleistocene climate change. Geomorphology 114, 440-452.

Verdu, J.M., Batalla, R.J., Martinez-Casasnovas, J.A., 2005. High-resolution grain-size characterisation of gravel bars using imagery analysis and geo-statistics. Geomorphology, 72, 73-93.

Wallis, E., MacNally, R., Lake, P.S., 2008. A Bayesian analysis of physical habitat changes at tributary confluences in cobble-bed upland streams of the Acheron River basin, Australia Water Resources Research 44, W11421.

Wellard Kelly, H.A., Rosi-Narshall, E.J., Kennedy, T.A., Hal, R.O., Cross, W.F., Baxter, C.V., 2013. Macroinvertebrate diets reflect tributary inputs and turbidity-driven changes in food 
availability in the Colorado River downstream of Glen Canyon Dam. Freshwater Science 32, 397-410.

Widder, S., Besemer, K., Singer, G.A., Ceola, S., Bertuzzo, E., Quince, C., Sloan, W., Rinaldo, A., Battin, T., 2014. Fluvial network organization imprints on microbial co-occurrence networks. Proceedings of the National Academy of Sciences of the United States of America $111,12799-12804$.

Wilson, M.J., McTammany, M.E., 2014. Tributary and mainstem benthic macroinvertebrate communities linked by direct dispersal and indirect habitat alteration. Hydrobiologia 783, 75-85.

Wipfli, M.S., Gregovich, D.P., 2002. Export of invertebrates and detritus from fishless headwater streams in southeastern Alaska: Implications for downstream salmonid production. Freshwater Biology 47, 957-969. 